\title{
Evaluating Twenty-eight Strains of 'Delicious' Apple in Michigan
}

\author{
F.G. Dennis, Jr., and J.G. Masabni \\ Department of Horticulture, Michigan State University, East Lansing, MI 48824-1325 \\ D.O. Ketchie \\ Tree Fruit Research Station, Washington State University, Wenatchee, WA 98801 \\ Additional index words. Malus domestica, yield, flowering, fruit set, fruit size, L/D ratio, biennial bearing index
}

\begin{abstract}
A cooperative experiment begun in 1980 was designed to evaluate the productivity and other characteristics of 16 spur and 12 standard strains of 'Delicious' apple on two rootstocks (M.7 EMLA and MM.111 EMLA). All trees were propagated at one nursery, and plantings were established in Michigan, Washington, Oregon, Idaho, Indiana, and British Columbia. In Michigan, trees of standard strains were consistently larger than trees of spur strains 8 years after planting. Early yields were greater on M.7 EMLA than on MM.111 EMLA, but trees were more subject to leaning under heavy crops on M.7 EMLA. In general, spur-type strains yielded more fruit per unit trunk cross-sectional area than standard strains. Yield was more closely associated with fruit-setting ability than with flower density, and fruit size declined as fruit set increased. Length/diameter ratios and biennial bearing indices also differed significantly among strains.
\end{abstract}

Many strains of the 'Delicious' apple have been identified since the cultivar was first introduced by Stark Brothers Nursery in 1896 (Fisher and Ketchie, 1981; Maas, 1970; Tukey and Ballard, 1969a, 1969b). They differ in vigor (spur vs. standard strains), as well as fruit color (single vs. double red, striped vs. blushed). Fisher and Ketchie (1981) reviewed the history and characteristics of many of these strains.

A cooperative 'Delicious' strain evaluation project was initiated in 1980 under the regional project WRCC-17 on flowering and fruit set. Trees of 28 strains (Table 1) propagated on two rootstocks, M.7 EMLA and MM.111 EMLA, hereafter referred to as M.7 and MM.111, were planted at nine locations in Washington, Oregon, Idaho, Indiana, Michigan, and British Columbia. Data for the Washington and Idaho sites (Fallahi et al., 1994, 1995; Ketchie, 1986), data for a similar study in West Virginia (Baugher et al., 1990), and data for the British Columbia site (Lane and MacDonald, 1996) have been published. Yield data for Michigan for 1 year were included in an analysis of strain and rootstock effects on spur characteristics and yield conducted in 1986 (Warrington et al., 1990), and all data on fruit color have been published (Dennis, 1989), as well as a brief summary (Dennis, 1990). This report presents complete data for the Michigan planting.

\section{Materials and Methods}

All trees were propagated by Oregon Rootstock Co. (now Treco), Woodburn, Ore. The Michigan experiment was conducted at the Clarksville Horticultural Research Station, Clarksville, Mich., 25 miles east of Grand Rapids. One-third of the planting was on Kalamazoo sandy loam, with some clay in the B horizon, and the other two-thirds on Bixby sandy loam, and soil type was considered in blocking the treatments. One tree of each strainrootstock combination was planted with a tree planter in each of six adjacent blocks at a spacing of $3.7 \times 5.5 \mathrm{~m}$ or 500 trees/ha. Idared/ M.7 trees were included as pollenizers (third tree in every third

Received for publication 20 Oct. 1995. Accepted for publication 18 June 1996. Research supported by the Michigan Agricultural Experiment Station. The cost of publishing this paper was defrayed in part by the payment of page charges. Under postal regulations, this paper therefore must be hereby marked advertisement solely to indicate this fact. row). Most trees were budded in 1978, and were 1-year-old whips when planted. These were headed at $75 \mathrm{~cm}$ immediately after planting. A few trees had just been bench-grafted. The trees were sorted according to size and blocked accordingly.

Cloth bags of human hair, tied on the trees to repel deer, were not removed until the following spring, when girdling by the strings was evident in some trees. If girdling was severe, trees were cut off below the girdle. Some of the bench grafts did not survive the first year. Extra trees from border rows were transplanted to replace trees lost, and rootstocks with dead scions were grafted with scions from appropriate strains where gaps occurred in the planting. Data were recorded for all trees, but tree size and yield data are presented only for original trees, and strain-rootstock combinations in which less than four original trees survived were excluded from statistical analysis (SS and SU on both rootstocks, HE on M.7, and IS and AO on M.111).

Pruning was minimal for the first 4 years, and, to allow comparison of growth habit, branches were not spread. Thereafter, competing branches were removed, vigorous terminal shoots were cut back about one-third to encourage branching, and multiple leaders were thinned to one shoot. The soil was cultivated the first year. A sod was established between rows the second year, and the soil under the trees was treated with herbicides to prevent weed growth. Drip irrigation was installed in 1985 and was used as needed thereafter. Recommended fertilizer applications were applied each spring. Many trees on M.7 rootstock began to lean once heavy cropping began. These were supported by stakes.

On each tree, one scaffold limb bearing 50 to 150 flower clusters was used to record the percentage of buds flowering and fruit set. Branch diameter at the base of the counted portion was measured, as well as trunk diameter $30 \mathrm{~cm}$ above the soil line (about $20 \mathrm{~cm}$. above the bud union). Cross-sectional areas were calculated so that number of flower clusters and fruit and total yield of fruit per tree could be expressed per square centimeter limb and trunk cross-sectional area (TCA). Samples (10 or 20 fruit per tree) were taken from the marked limb and from a similar limb on the opposite side of the tree at harvest, and total weight of fruit per tree was recorded annually. The samples were used to obtain data on fruit weight, length, and diameter. Total tree height and spread (average of two measurements at right angles) were measured to the nearest $25 \mathrm{~cm}$ in the dormant period during the first 7 years. No 
Table 1. 'Delicious' strains compared, abbreviations used, and original source.

\begin{tabular}{|c|c|c|}
\hline Strain & Abbreviation & Nursery \\
\hline \multicolumn{3}{|c|}{ Spur strains } \\
\hline Ace & $\mathrm{AC}$ & Columbia Basin \\
\hline Apex & AP & Columbia Basin \\
\hline Atwood & AT & Yakima Valley \\
\hline Hardi-brite Spur & $\mathrm{HB}$ & Carlton \\
\hline Hardispur & HS & Carlton \\
\hline Improved Ryan Spur & IS & Carlton \\
\hline Redchief (Campbell) & $\mathrm{RC}$ & Hilltop \\
\hline Red King Oregon Spur & RK & Van Well \\
\hline Redspur & $\mathrm{RS}$ & $\mathrm{C}$ and $\mathrm{O}$ \\
\hline Silver Spur & SI & Bountiful Ridge \\
\hline Spured Royal & SR & $\mathrm{C}$ and $\mathrm{O}$ \\
\hline Starkrimson (Bisbee) & SN & Stark Brothers \\
\hline Starkspur Supreme & SS & Stark Brothers \\
\hline Starkspur Ultra Red & SU & Stark Brothers \\
\hline Sturdeespur (Miller Sturdeespur) & SD & Hilltop \\
\hline Wellspur & WS & Van Well \\
\hline \multicolumn{3}{|c|}{ Standard strains } \\
\hline Aomori & $\mathrm{AO}$ & Stark Brothers \\
\hline August Red & AU & Heath \\
\hline Classic Red & CL & $\mathrm{C}$ and $\mathrm{O}$ \\
\hline Early Red One & ER & Van Well \\
\hline Hi-Early & $\mathrm{HE}$ & Heath \\
\hline Imperial & IM & Hilltop \\
\hline Improved Ryanred & IR & Carlton \\
\hline Nured Royal & NR & $\mathrm{C}$ and $\mathrm{O}$ \\
\hline Rose Red & RO & McCormick \\
\hline Sharp Red & $\mathrm{SH}$ & Van Well \\
\hline Starking (Mood) & SG & Stark Brothers \\
\hline Topred & TR & $\mathrm{C}$ and $\mathrm{O}$ \\
\hline
\end{tabular}

chemical thinners were applied, but heavily cropping trees were hand thinned in late July or early August 1986 to prevent limb breakage. No correction was made for fruit removed in calculating total yield. Harvested fruit and windfalls were included in total yield.

Biennial bearing index. Biennial tendency was evaluated for years $1984-87$ by calculating the biennial bearing index (Hoblyn, et al. 1956):

1/3[|Yield 1985 - Yield 1984|/Total yield $1984+1985+\ldots+$

|Yield 1987 - Yield 1986|/Total yield $1986+1987]$

using yield $/ \mathrm{cm}^{2}$ trunk cross-section for each replicate tree. This provided three values per tree for years 1984-85, 1985-86, and 1986-87. Strain means were analyzed statistically, using years as blocks.

Statistical analysis. The SAS GCM program was used first to analyze data for all strains on both rootstocks, with four to six replicate trees per strain-rootstock combination. However, strainrootstock interaction was significant in essentially all comparisons. Therefore, data for each rootstock were analyzed separately, using the nonorthogonal program in MSTAT-C to allow for unequal numbers of replicates (blocks) among strains.

In calculating biennial bearing index and trunk and canopy diameter, data for each tree were analyzed. Mean values for each strain-rootstock for each of 4 years (1984-87) were used in statistical analysis of all other comparisons among strains within rootstocks. Some rootstock and spur vs. standard strain effects were analyzed by using mean values across all years in a one-way analysis of variance. The same procedure was used for similar comparisons, using published data for parallel trials in other states.

\section{Results}

Trunk and canopy diameter. Average trunk and canopy diameters were larger in standard than in spur strains with few exceptions, although differences between the smallest standard strains (e.g., ER, IM) and the largest spur strains (e.g., AP, RS, WS) were generally nonsignificant (Fig. 1). Less variation was evident among spur-type strains on M.7 than among those on M.111. Rankings among strains varied with rootstock, although SR trees were relatively small on both rootstocks, and ER and IM trees were among the smallest within standard strains. Trunk diameter (Fig. $1 \mathrm{~A}$ and B) roughly paralleled canopy diameter (Fig. $1 \mathrm{C}$ and D).

Yield per tree. AP, ER, RK, SD, and SI were among the most productive strains on both rootstocks, based on yield per tree. When propagated on M.7, spur strains were generally more productive than standard strains ( 33.1 vs. $25.8 \mathrm{~kg} /$ tree, $P<0.01)$, but this was not true of trees on M.111 (31.5 vs. $29.3 \mathrm{~kg} /$ tree) (Fig. 2 A and B). On M.7, highest yields were obtained from AP, IS, RK, SI, and SD among spur strains and from ER and RO among standards (Fig. 2A), and lowest yields from RC and WS (spurs) and NR, SH, and TR (standards). On M.111, AP, RK, SI, SD, SU, and WS were the most productive spur strains, AU and ER the most productive standards (Fig. 2B), while RC (spur) and SH and TR (standards) were least productive. In general, standard strains yielded more on M.111 than on M.7 rootstocks.

Yield efficiency. With few exceptions, spur strains on both rootstocks were more efficient than standard strains when yields were corrected for tree size ( $860 \mathrm{vs.} 440 \mathrm{~g} \cdot \mathrm{cm}^{-2}$ on M.7, 647 vs. 411 

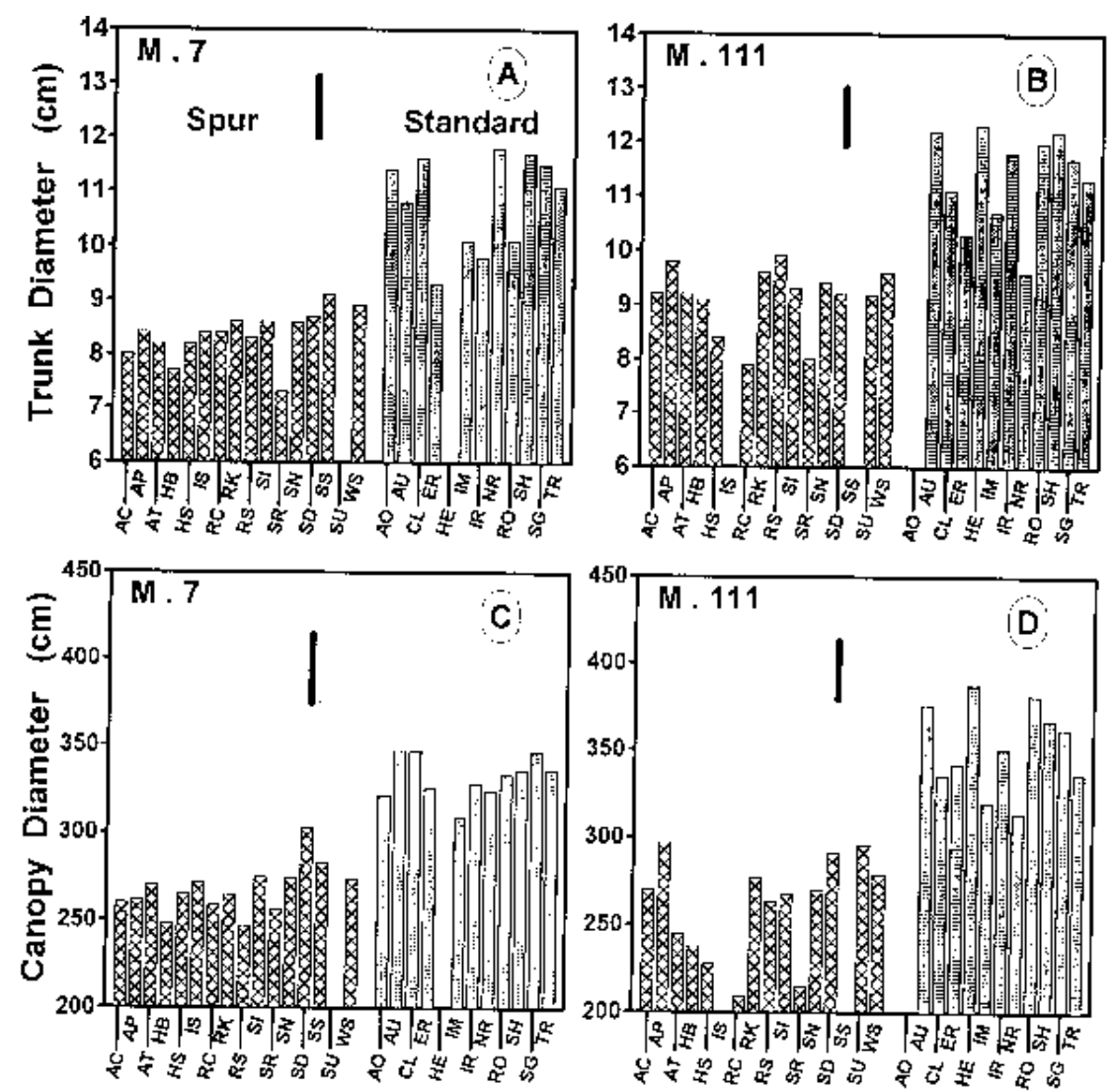

Strain
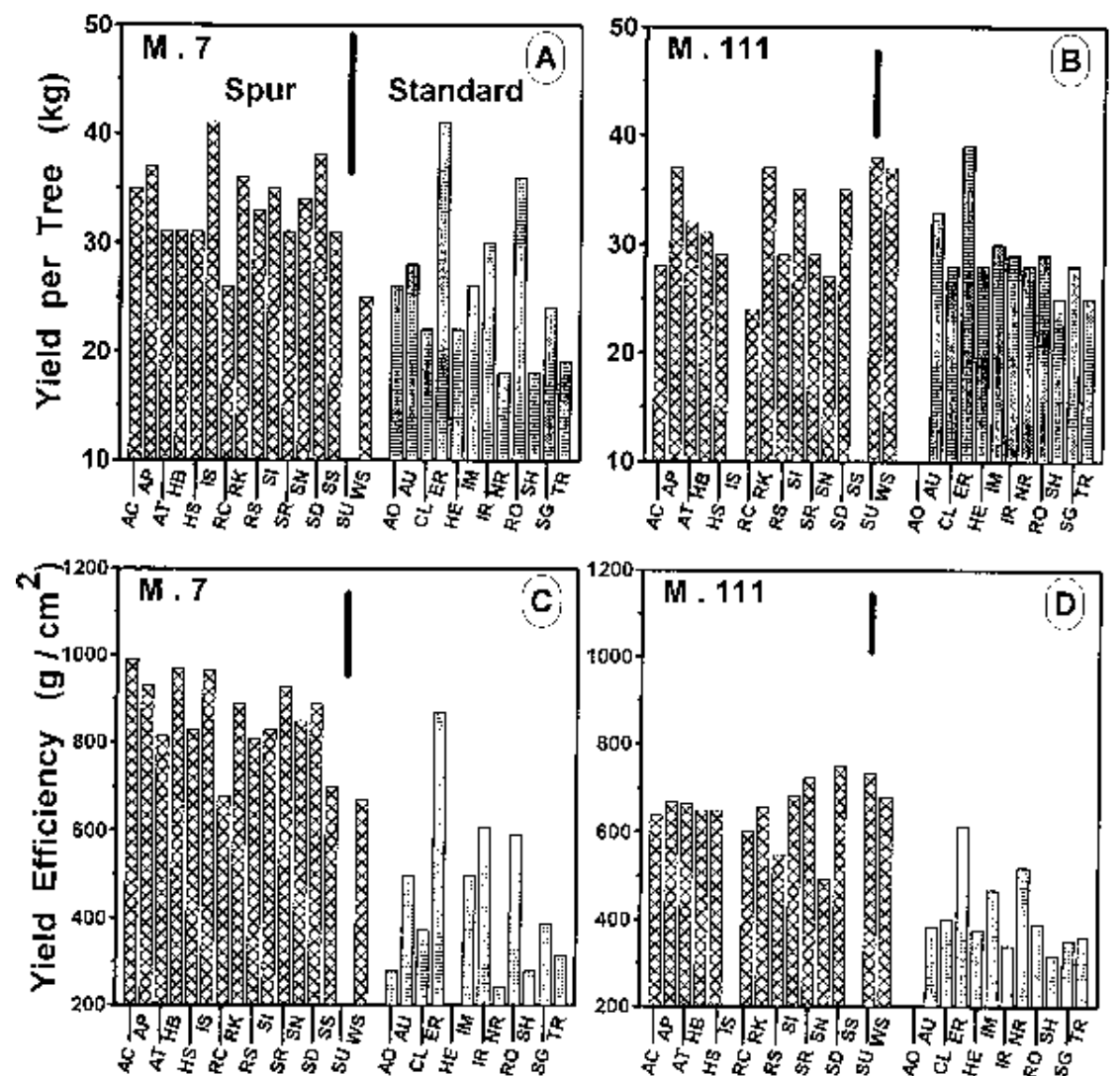

Strain
Fig. 1. Trunk (A and $\mathbf{B})$ and canopy diameters $(\mathbf{C}$ and $\mathbf{D})$ of 28 'Delicious' strains on M.7 (A and C) and MM.111 (B and D) rootstocks at the end of the growing season in 1987. (See Table 1 for full names of strains.) Data omitted for strain-rootstock combinations with less than four surviving trees of original six, but strain code is included to facilitate comparisons across rootstocks. Vertical bar is LSD 0.05 .

$\mathrm{g} \cdot \mathrm{cm}^{-2}$ on M.111, both significant at $P<0.0001$ ) (Fig. 2. C and D); ER was an exception among the standard strains in this regard. On M.7, RC, SS, and WS were the least productive spur strains, paralleling yield per tree for these strains, and did not differ significantly from the standard strains AU, IR, IM, and RO (Fig. 2C). Differences among the other spur strains were nonsignificant. On M.111 (Fig. 2D), yield efficiency of the least productive spur strains (e.g., RS and SN) did not differ significantly from that of the most productive standards (e.g., ER and NR). Differences among the other spur strains were nonsignificant. Yield efficiency of ER was significantly greater than that of all other standard strains except NR. Spur strains propagated on M.7 generally outperformed those on M.111, but this was not true of standard strains (significance not tested because of interaction).

Yield efficiency vs. flower density. Yield was not significantly correlated with flower density (flower clusters $/ \mathrm{cm}^{2}$ limb cross-section) when each rootstock and type of strain (spur vs. standard) was analyzed separately (Fig. 3 A and B, Table 2), but the relationship in M.7 was significant when data for all strains were combined (Table 2). Standard strains yielded less than spur strains at identical flower densities; thus, differences in flowering were not responsible for the differences in yield observed between spur and standard trees. The standard strain ER yielded as well as spur strains and, therefore, appears in the same region of the graphs, whereas values for spur strains with relatively low yields (e.g., RC, SS, and WS on M.7) were similar to those for some of the more productive standard strains. The range of flower density values was similar in trees on both M.7 and M.111, but yields were higher in spur types propagated on M.7.

Yield efficiency vs. fruit set. Yield efficiency was significantly correlated with fruit set only for standard strains on M.7 and spur strains on M.111 when data were not pooled for all strains within rootstocks (Table 2). When data for all strains were combined, the correlation was significant for both rootstocks ' (Table 2, Fig. $3 \mathrm{C}$ and D). Spur strains on M.7 + consistently set better than standards with two ex- ceptions: ER (standard) set as well as spur strains and i RC (spur) set no better than IR (nonspur). Among : spur strains on M.111, only values for HS were as I low as those for standards (Fig. 4D). The slope of the 1 regression line for M.7 was greater than that for

\footnotetext{
Fig. 2. Mean yield per tree (A and $\mathbf{B})$ and mean yield efficiency $(\mathbf{C}$ ¿ and D) 1984-87 of 'Delicious' strains on M.7 (A and C) and MM.111 (B and D) rootstocks. (See Table 1 for full names of strains.) Data omitted for strain-rootstock combinations with less than four original trees. Vertical bar is LSD 0.05 .
} 

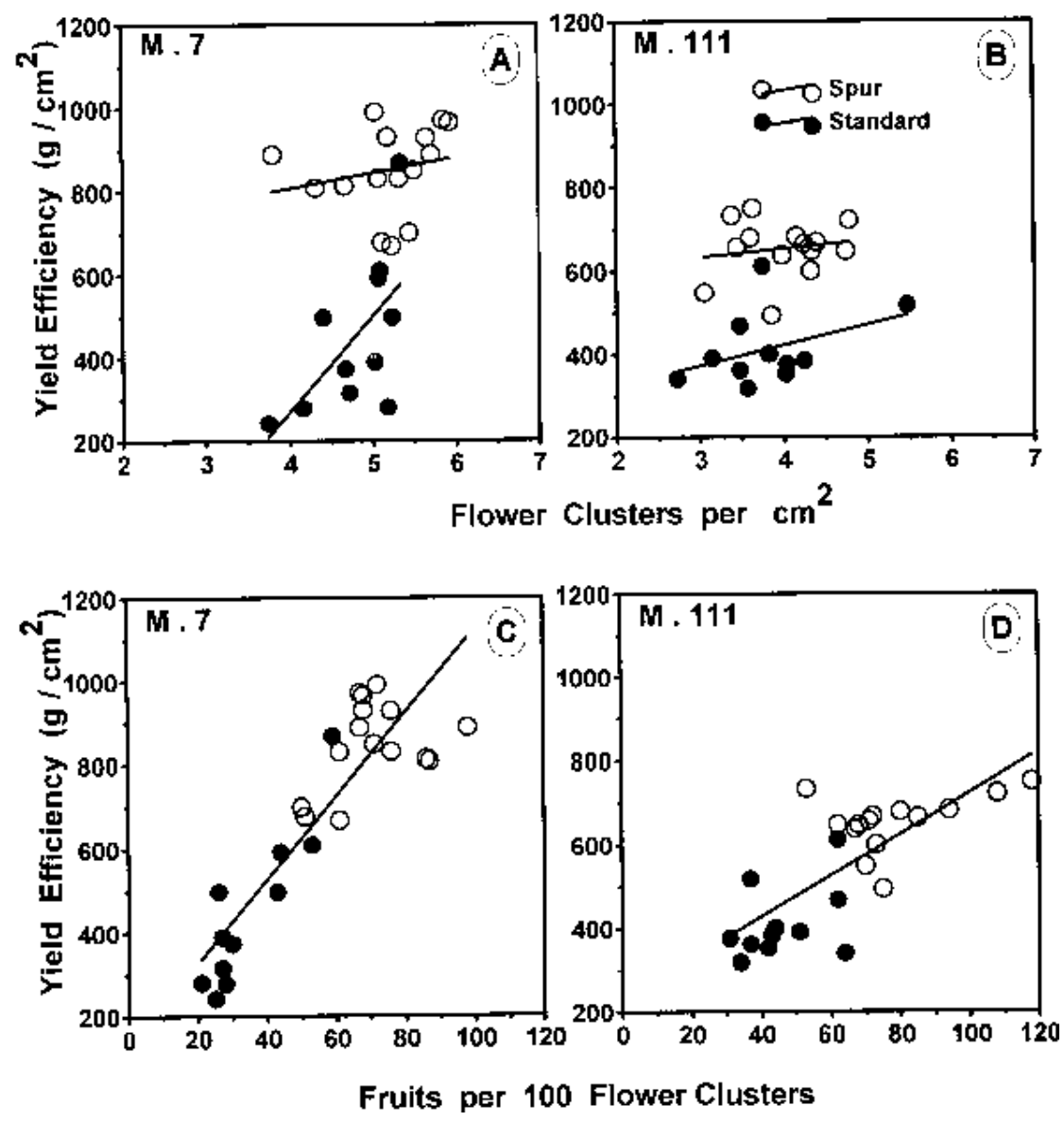

Fig. 3. Yield efficiency vs. flower density (A and $\mathbf{B})$ and vs. fruit set (C and D) in 'Delicious' strains propagated on M.7 (A and C) and MM.111 (B and D) rootstocks. Each point is the average for one strain for 4 years. (See Table 2 for $r$ values.)

pattern within spur vs. standard strains. Although spur strains on M.7 had higher yield efficiencies than those on M.111, fruit size was similar on both rootstocks. Had mean weights of all fruit on each tree been determined, rather than those of small samples, $r$ values would presumably have been larger.

Because size increases as fruit load decreases, plotting weight per fruit vs. yield efficiency $\left(\mathrm{g} \cdot \mathrm{cm}^{-2}\right.$ trunk cross-section) does not give a true estimate of the effect of fruit density on size. Therefore, the number of fruit per unit branch cross-sectional area on count limbs was calculated and plotted against weight per fruit (Fig. $4 \mathrm{C}$ and D). Again, fruit weight declined as fruit load increased, and the variability was reduced somewhat (Table 2 ). However, many strains with very similar crop loads still differed greatly in fruit weight. Even when covariance was used to factor out crop load, significant differences in fruit weight were apparent among strains on both rootstocks (data not shown), and the relative positions of the strains changed little. RK and $\mathrm{AC}$ tended to produce large fruit relative to fruit density on both stocks; on M.111, NR fruit were also relatively large. In contrast, SN fruit tended to be small on both stocks. On M.7, WS and SH also produced small fruit; on M.111, SG and TR tended to be small.

M.111, again reflecting higher yields in spur strains on M.7.

Yield efficiency vs. fruit weight. When all strains were included, yield efficiency on both rootstocks was negatively correlated (significant at $P<0.01$ or 0.001 ) with fruit weight (Fig. 4 A and B, Table 2), as might be expected, based on the effects of crop load on fruit size. However, $r$ values were nonsignificant within spur vs. standard strains (Table 2). Considerable variation was evident in these data. Large differences were evident between spur vs. standard strains within rootstocks, the former producing smaller fruit and higher yields than the latter. However, there was no
Biennial bearing index. Biennial bearing index for the 4 years of observation (1984-87) varied from a high of 0.5 (SH) to a low of 0.19 (RK) on M.7, but only the highest (SH and SG, with values of 0.50 and 0.48 , respectively) and lowest (0.19 to 0.32 ) values differed significantly (Fig. 5A). Among strains propagated on M.111 (Fig. 5B), only values for SN, HE, and IR (0.46 to 0.52$)$ were significantly greater than those for the least biennial strains (0.22 to 0.29$)$; SN had a significantly higher index than other spur strains. Values for standard strains tended to be higher than those for spur strains on both rootstocks; ER was a notable exception.

Table 2. Correlation of yield efficiency vs. parameters of yield and of fruit density vs. weight per fruit for 'Delicious' apples, 1984-87.

\begin{tabular}{|c|c|c|c|}
\hline \multirow[b]{2}{*}{ Parameter } & \multirow[b]{2}{*}{ Strain } & \multicolumn{2}{|c|}{ Rootstock } \\
\hline & & M.7 & M.111 \\
\hline \multicolumn{4}{|c|}{$\overline{\text { Yield/efficiency }\left(\mathrm{g} \cdot \mathrm{cm}^{-2}\right) \mathrm{vs} .}$} \\
\hline \multirow[t]{3}{*}{ Flower clusters $/ \mathrm{cm}^{2}$} & Standard & 0.617 & 0.392 \\
\hline & Spur & 0.276 & 0.344 \\
\hline & All & $0.510^{* *}$ & 0.354 \\
\hline \multirow[t]{3}{*}{ Fruit/100 clusters } & Standard & $0.906^{* *}$ & 0.402 \\
\hline & Spur & 0.279 & $0.616^{*}$ \\
\hline & All & $0.888^{* *}$ & $0.820^{* * *}$ \\
\hline \multirow[t]{3}{*}{ Weight/fruit } & Standard & -0.290 & -0.326 \\
\hline & Spur & -0.281 & -0.214 \\
\hline & All & $-0.583^{* *}$ & $-0.643^{* *}$ \\
\hline \multirow{4}{*}{$\begin{array}{l}\text { No. fruit } / \mathrm{cm}^{2} \text { (limb basis } \\
\text { weight/fruit }\end{array}$} & & & \\
\hline & Standard & -0.235 & -0.570 \\
\hline & Spur & -0.310 & -0.194 \\
\hline & All & $-0.670^{* *}$ & $-0.701^{* *}$ \\
\hline
\end{tabular}

$\mathrm{z}_{\mathrm{n}}=11,14$, and 25 for standard, spur, and all strains on M.7 (11, 12, and 23 for M.111).

${ }^{*}, * *$ Significant at $P<0.05$ or 0.01 , respectively; other values nonsignificant at $P<0.05$. 
Fig. 4. Yield efficiency vs. fruit weight (A and $\mathbf{B}$ ) and vs number of fruit per square centimeter cross-sectional area of count limbs (C and D) in 'Delicious' strains propagated on M.7 (A and C) and MM.111 (B and D) rootstocks. Each point is the average for one strain for 4 years. (See Table 2 for $r$ values.)

Index values were also calculated for the 3 years 1986-88, but differences were not significant with either rootstock (data not shown).

Length/diameter ratio. L/D ratios were generally higher in spur than in standard strains $(0.962$ vs. 0.943 on M.7, 0.971 vs. 0.954 on M.111, $P<$ 0.001 for both) and in trees propagated on M.111 than in those on M.7 (Fig. 6). Among spur strains, $\mathrm{L} / \mathrm{D}$ ratios of $\mathrm{HB}, \mathrm{SI}$, and $\mathrm{SN}$ were consistently high on both rootstocks; among standards, CL, ER, HE, and SG were consistently high. Values for AU, IR, and RO were low on M.7; TR and AO exhibited relatively low values on M.111. L/D ratio was negatively correlated with fruit weight on M.111 ( $r$ $\left.=0.703^{* * *}\right)$, but not on M.7 $(r=0.241)$.

\section{Discussion}

Cultivar and strain evaluation is fraught with difficulties because of the possible effects of soil type, climate, and cultural practices. Participants in this cooperative project expected to overcome some of these difficulties by using the same strainrootstock combinations, pollenizers, and planting distances at eight different sites ranging from British Columbia to Michigan. Despite common protocol, strain differences were expected among sites. Given unlimited resources, several sites could have been used in each state or province to evaluate climatic effects better. This was done in Washington, Oregon, and Indiana, but not in other states.

Warrington et al. (1990), using data from the Clarksville planting in 1986, demonstrated significant correlations $(r)$ between spur density and a) trunk cross-sectional area $\left(-0.56^{* *}\right)$ and b) yield efficiency $\left(0.23^{* *}\right)$, spur strains having consistently higher yields and spur densities, and lower cross-sectional areas, than standard strains. Our data for 1984-87 confirm that trees of spur strains generally yielded more fruit per unit trunk cross-section and were smaller than standard trees. Statistical analysis of published data indicated that differences between all spur vs. all standard strains were significant in Washington $(P<0.01)$, Idaho $(P<$ $0.001)$, and West Virginia $(P<0.03)$. Average yield efficiencies for spur vs. standard strains on M.7 in Michigan (840 vs. 440 $\mathrm{g} \cdot \mathrm{cm}^{-2}$ ) were higher than those reported in Washington (559 vs. $294 \mathrm{~g} \cdot \mathrm{cm}^{-2}$ ), Idaho (308 vs. $229 \mathrm{~g} \cdot \mathrm{cm}^{-2}$ on an annual basis) and West Virginia (336 vs. $201 \mathrm{~g} \cdot \mathrm{cm}^{-2}$ ).

Lane et al. (1996) reported better red coloration in standard strains than in spur strains grown at Summerland, B.C. However, data from Michigan (Dennis, 1989), Idaho (Fallahi et al., 1994), Pennsylvania (Crassweller, et al., 1991), and West Virginia (Baugher et al., 1990; Crassweller et al., 1991) reveal no consistent relationship between growth habit and degree of coloration.

L/D ratio is a selling point for 'Delicious'; those with high L/D ratios (typey fruit) are favored over flatter fruit. Part of the appeal of such fruit is their greater size, as fruit weight increases with typiness when diameter is held constant. Consumers presumably would prefer typey fruit, if only for this reason.

Although the positive correlation between fruit load and L/D
M. 7

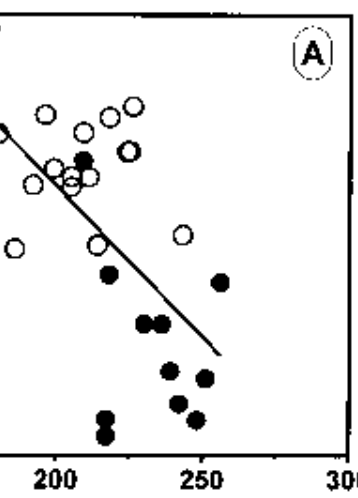

A)

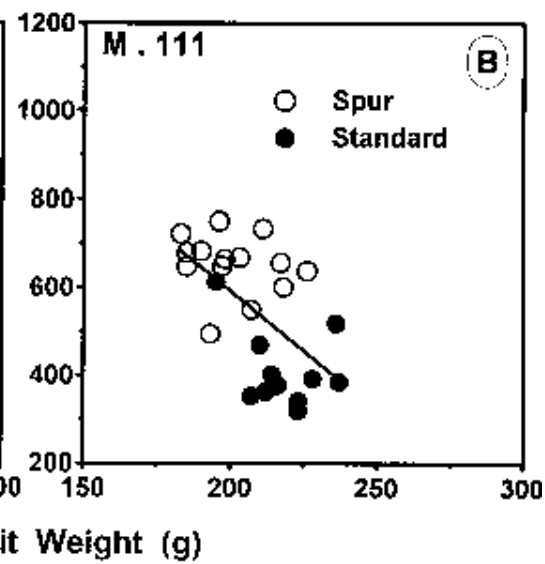

Fruit Weight (g)
M. 7

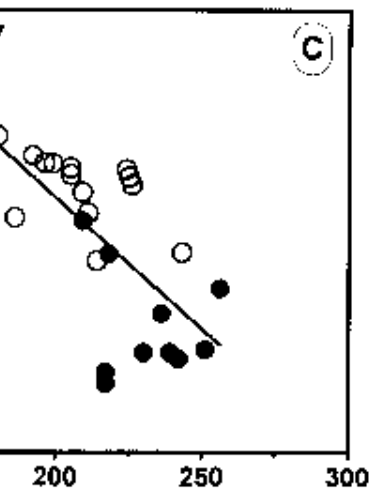

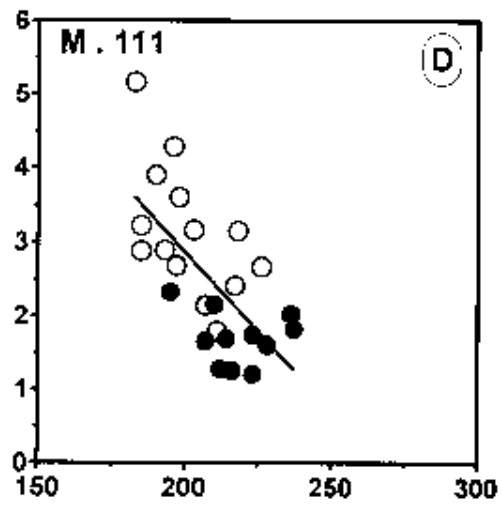

Fruit Weight (g)

ratio observed by Westwood and Blaney (1963) was not found in this study, L/D ratio of strains on M.111 declined as fruit weight increased, as would be predicted from the data of Westwood and Bjornstad (1968). Although L/D ratio overall was negatively correlated with fruit size, individual differences among strains in L/D ratio were not necessarily associated with size. Westwood and Blaney (1963) reported higher L/D ratios in fruit of Starkrimson 'Delicious' (spur type) than in standard strains. Lane et al. (1996), however, reported no major differences in L/D ratios for spur vs. standard strains.

The greater L/D ratios that we observed on spur strains confirm the data obtained in Idaho $(0.991$ and 0.981 for spurs and standards, respectively; $P<0.02$ on recalculation from tabled means). Differences in West Virginia, however, were not significant $(P=0.119)$. In neither Idaho nor West Virginia was L/D ratio significantly correlated with yield efficiency when correlation coefficients were calculated from the published data.

Barritt et al. (1994) measured L/D ratios of Starkspur Supreme and Redchief 'Delicious' on 17 (Starkspur Supreme) or 23 (Redchief) rootstocks over 2 years. In both strains and years, L/D ratios increased with rootstock vigor, with $r^{2}$ values ranging from 0.4 to 0.83 . Differences between dwarf and intermediate vigor stocks were greater than those between intermediate and vigorous stocks. M.111 was not included in the study, but the ratios on M.7A or M.7E tended to fall near the middle to upper portion of the range.

Comparison of major effects from several locations. Comparison of the Michigan data with those for other sites is complicated by differences in time of data collection. Nevertheless, we have attempted to make a rough comparison by listing (Table 3) the strains with the largest and smallest values for each of three parameters - trunk diameter or cross-sectional area, yield per tree, 




Strain

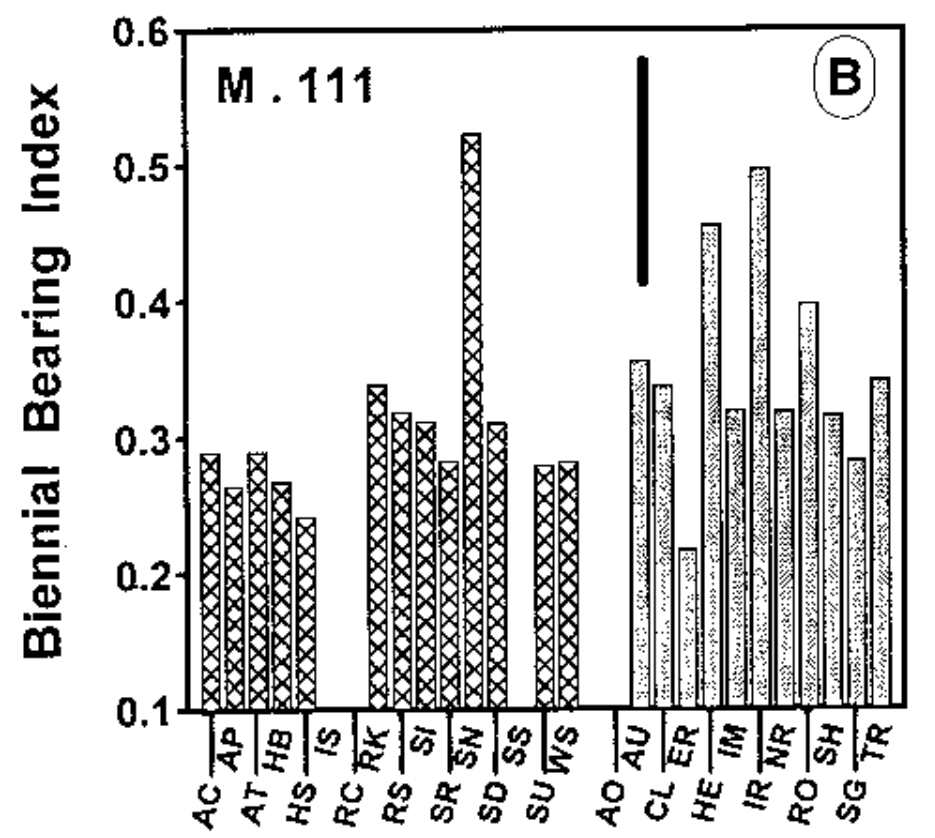

\section{Strain}

Fig. 5. Biennial bearing indices of 'Delicious' strains propagated on M.7 (A) and MM.111 (B) rootstocks, 1984-87. (See Table 1 for full names of strains.) Data omitted for strains with less than four surviving trees of original six. Vertical bar is LSD 0.05 .

and yield efficiency. Plantings in Washington, Idaho, Oregon, and British Columbia were a part of the original experiment (planted 1980), but that in West Virginia (planted 1981) was not. Some strains are omitted from the comparisons because they were not planted, were propagated on a different rootstock, or too few data were available.

Tree size, as reflected in trunk diameter or cross-sectional area, was greatest for standard strains and least for spur strains with but one exception (RK in West Virginia). AU, CL, SG, and SH were among the largest strains, and HS and SR among the smallest
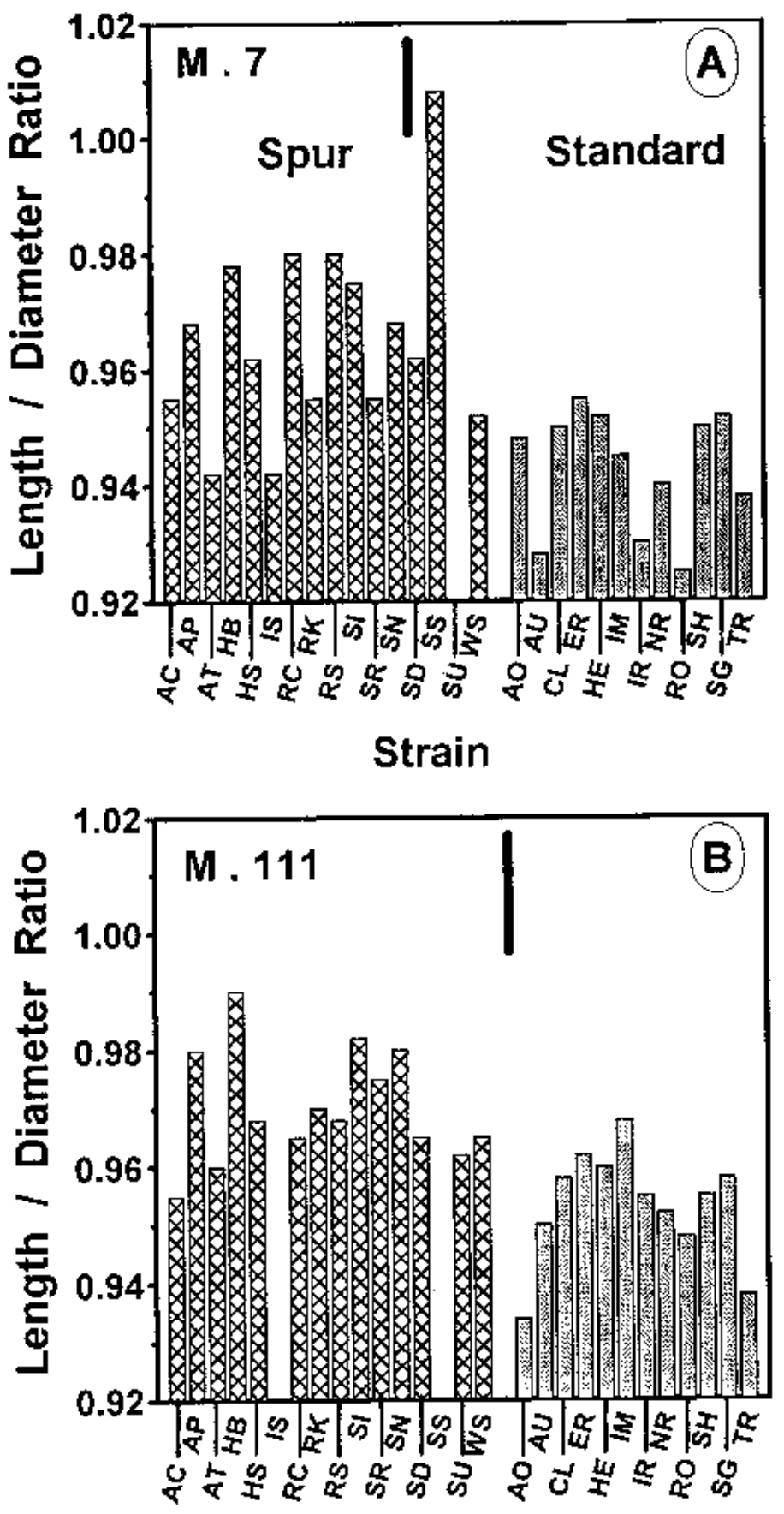

\section{Strain}

Fig. 6. Length/diameter ratios of fruit of 'Delicious' strains, propagated on M.7 (A) and MM.111 (B) rootstocks, 1984-87. (See Table 1 for full names of strains.) Data omitted for strains with less than four surviving trees of original six. Vertical bar is LSD 0.05 .

(listed four to six times among seven site-rootstock comparisons).

Yield per tree was less affected by growth habit; spurs and standards were found among the highest and lowest yielding strains. AP, SD, and SG were the highest yielding strains on a per tree basis (listed three to six times among nine comparisons), and $\mathrm{TR}$ and $\mathrm{SH}$ among the lowest (three to five listings among nine comparisons).

Yield efficiency was consistently greatest in spur strains and lowest in standards, with but few exceptions (SS and SU in 
Table 3. Relative performance of 'Delicious' strains at six sites. , $^{\text {,y }}$

\begin{tabular}{|c|c|c|c|c|c|c|c|c|c|}
\hline \multirow[b]{3}{*}{ Rootstock } & \multicolumn{9}{|c|}{ Site } \\
\hline & \multicolumn{2}{|c|}{ MI } & \multicolumn{2}{|c|}{ WA } & \multirow{2}{*}{$\begin{array}{c}\text { ID } \\
7\end{array}$} & \multirow{2}{*}{$\begin{array}{c}\text { WV } \\
7\end{array}$} & \multicolumn{2}{|c|}{ OR } & \multirow{2}{*}{$\begin{array}{c}\mathrm{BC}^{\mathrm{x}} \\
7 / 111\end{array}$} \\
\hline & 7 & 111 & 7 & 111 & & & 7 & 111 & \\
\hline \multicolumn{10}{|c|}{ Trunk size } \\
\hline \multirow[t]{5}{*}{ Maximum } & AO* & $\mathrm{AU}^{*}$ & $\mathrm{AU}^{*}$ & $\mathrm{HE}^{*}$ & $\mathrm{AU}^{*}$ & $\mathrm{AO}^{* \mathrm{w}}$ & --- & --- & $\mathrm{AU}^{*}$ \\
\hline & CL* & $\mathrm{HE}^{*}$ & $\mathrm{CL}^{*}$ & $\mathrm{NR}^{*}$ & $\mathrm{CL}^{*}$ & $\mathrm{CL}^{*}$ & --- & --- & $\mathrm{CL}^{*}$ \\
\hline & $\mathrm{NR}^{*}$ & $\mathrm{IR}^{*}$ & $\mathrm{SH}^{*}$ & $\mathrm{SG}^{*}$ & RO* & $\mathrm{RK}$ & --- & --- & HE* \\
\hline & $\mathrm{SG}^{*}$ & RO* & $\mathrm{SG}^{*}$ & --- & $\mathrm{SG}^{*}$ & $\mathrm{SH}^{*}$ & --- & --- & $\mathrm{SG}^{*}$ \\
\hline & $\mathrm{SH}^{*}$ & $\mathrm{SH}^{*}$ & --- & --- & $\mathrm{SH}^{*}$ & $\mathrm{TR}^{*}$ & --- & --- & $\mathrm{SH}^{*}$ \\
\hline \multirow[t]{5}{*}{ Minimum } & $\mathrm{AC}$ & $\mathrm{HB}$ & IS & HS & $\mathrm{AT}$ & $\mathrm{AC}$ & --- & --- & HB \\
\hline & $\mathrm{AT}$ & HS & $\mathrm{RC}$ & $\mathrm{RC}$ & HB & $\mathrm{AP}$ & --- & --- & HS \\
\hline & $\mathrm{HB}$ & $\mathrm{RC}$ & RK & SS & HS & SD & --- & --- & $\mathrm{RC}$ \\
\hline & HS & SD & SR & SU & RK & SI & --- & --- & SR \\
\hline & SR & SR & SU & --- & SR & SR & --- & --- & SU \\
\hline \multicolumn{10}{|c|}{ Yield/tree } \\
\hline \multirow[t]{5}{*}{ Maximum } & $\mathrm{AP}$ & $\mathrm{AP}$ & $\mathrm{AT}$ & $\mathrm{AP}$ & $\mathrm{AU}^{*}$ & $\mathrm{AC}$ & $\mathrm{AC}$ & $\mathrm{AP}$ & $\mathrm{AC}$ \\
\hline & $\mathrm{ER}^{*}$ & $\mathrm{ER}^{*}$ & RK & IS & $\mathrm{AP}$ & $\mathrm{IM}^{*}$ & $\mathrm{AU}^{*}$ & $\mathrm{AU}^{*}$ & $\mathrm{AP}$ \\
\hline & IS & RK & $\mathrm{RS}$ & $\mathrm{NR}^{*}$ & IS & RK & $\mathrm{IR}^{*}$ & $\mathrm{HE}^{*}$ & IS \\
\hline & RO* & SU & SI & $\mathrm{RS}$ & $\mathrm{SG}^{*}$ & SD & $\mathrm{SG}^{*}$ & $\mathrm{SG}^{*}$ & SD \\
\hline & SD & WS & SR & $\mathrm{SD}$ & SI & SI & SN & SN & SS \\
\hline \multirow[t]{5}{*}{ Minimum } & CL* & $\mathrm{HE}^{*}$ & $\mathrm{AO}^{*}$ & $\mathrm{AO}^{*}$ & HS & CL* & $\mathrm{AO}^{*}$ & $\mathrm{AO}^{*}$ & $\mathrm{AO}^{*}$ \\
\hline & $\mathrm{HE}^{*}$ & $\mathrm{RC}$ & $\mathrm{NR}^{*}$ & $\mathrm{IM}^{*}$ & $\mathrm{IM}^{*}$ & $\mathrm{RO}^{*}$ & HS & HS & CL* \\
\hline & $\mathrm{NR}^{*}$ & $\mathrm{SH}^{*}$ & $\mathrm{RC}$ & SS & IR & $\mathrm{SH}^{*}$ & NR & IS & $\mathrm{HE}^{*}$ \\
\hline & $\mathrm{SH}^{*}$ & $\mathrm{SN}$ & $\mathrm{RO} *$ & $\mathrm{SU}$ & SS & $\mathrm{TR}^{*}$ & RK & RK & RO* \\
\hline & $\mathrm{TR} *$ & $\mathrm{TR}^{*}$ & SU & $\mathrm{TR}^{*}$ & $\mathrm{TR}^{*}$ & WS & SU & SU & SU \\
\hline \multicolumn{10}{|c|}{ Yield efficiency } \\
\hline \multirow[t]{5}{*}{ Maximum } & $\mathrm{AC}$ & SD & $\mathrm{AT}$ & $\mathrm{AP}$ & HB & $\mathrm{AC}$ & --- & --- & $\mathrm{AC}$ \\
\hline & AP & SI & RK & IS & IS & AP & --- & --- & HB \\
\hline & $\mathrm{HB}$ & SR & RS & $\mathrm{RC}$ & RK & $\mathrm{IM}^{*}$ & --- & --- & IS \\
\hline & IS & WS & SI & $\mathrm{RS}$ & SI & RS & --- & --- & RS \\
\hline & SR & SU & SR & SR & SR & SI & --- & --- & SD \\
\hline \multirow[t]{5}{*}{ Minimum } & $\mathrm{AO}^{*}$ & $\mathrm{HE}^{*}$ & $\mathrm{AO}^{*}$ & $\mathrm{AO}^{*}$ & $\mathrm{AC}$ & $\mathrm{AO}^{* \mathrm{w}}$ & --- & --- & $\mathrm{AO}^{*}$ \\
\hline & $\mathrm{HE}^{*}$ & $\mathrm{IR}^{*}$ & $\mathrm{IM}^{*}$ & $\mathrm{IM}^{*}$ & $\mathrm{IR}^{*}$ & CL* & --- & --- & $\mathrm{CL}^{*}$ \\
\hline & $\mathrm{NR}^{*}$ & $\mathrm{SH}^{*}$ & SS & SS & RO* & $\mathrm{RO}^{*}$ & --- & --- & $\mathrm{HR}^{*}$ \\
\hline & $\mathrm{SH}^{*}$ & $\mathrm{SG}^{*}$ & SU & $\mathrm{SU}$ & $\mathrm{SH}^{*}$ & $\mathrm{SH}^{*}$ & --- & --- & $\mathrm{SH}^{*}$ \\
\hline & $\mathrm{TR} *$ & $\mathrm{TR}^{*}$ & $\mathrm{TR}^{*}$ & $\mathrm{TR} *$ & $\mathrm{TR}^{*}$ & $\mathrm{TR}^{*}$ & --- & --- & SU \\
\hline
\end{tabular}

z'Sources: Washington—Ketchie (1986); Idaho-Fallahi et al. (1994); West Virginia—Baugher et al. (1990); Oregon—E.A. Mielke (unpublished data); British Columbia-Lane et al. (1996).

'Data for 1984-87 (Michigan, Oregon), 1981-85 (Washington), 1986 and 1990-92 (Idaho), and 1985-88 (W. Virginia). Data for British Columbia are for 1988 (trunk size and yield efficiency) or 1984-87 (yield per tree).

${ }^{x}$ Based on means across rootstocks.

wPlanted 1982; all other strains planted in 1981 at this site.

*Standard strain; all others spur strains.

Washington, and SU in British Columbia). AP, RS, SI, and SR were conspicuous among high yielding strains (three to five listings among seven comparisons), while TR, AO, and SH yielded poorly (five to six listings among six to seven comparisons). TR was among the lowest yielding strains at all sites.

Our data indicate that yield efficiency of certain strains, particularly the standard strains AO, HE, SH, SG, and TR were low. Selection of spur strains on the basis of yield alone would be unwise, given rootstock differences and the relatively small differences among strains on the same rootstock. Aside from Starking, color differences would rule out few strains, unless fruit were to be harvested for sale before maturity. Many Washington growers are encouraged to grow striped, rather than blushed, strains to standardize the product and to avoid very dark fruit. Early Red One would probably be excluded because of its deep red, almost purple, color. This is not a major consideration in Michigan, however.
Commercial apple production practices are changing rapidly; when this study was planned in the late 1970s, most growers were using freestanding trees on semidwarf stocks. Today many growers prefer more dwarfing stocks, combined with tree supports. Some spur type 'Delicious' strains may not be sufficiently vigorous when grafted on full dwarf stocks. Nevertheless, our data provide a more objective basis for selection of strains. For example, using the standard strain Early Red One on a full dwarfing stock might provide the greater vigor needed plus high yield.

\section{Literature Cited}

Baugher, T.A., S. Singha, E.C. Townsend, and M. Ingle. 1990. Growth, yield and fruit quality of 'Delicious' apple strains. W. Va. Agr. For. Expt. Sta. Bul. 702.

Barritt, B.H., M.A. Dilley, and A.S. Konishi. 1994. Influence of rootstock on 'Delicious' apple fruit shape. Fruit Var. J. 48:126-130. 
Crassweller, R.M., H.L. Braun, T.A. Baugher, G.M. Greene, II, and R.A. Hollendar. 1991. Color evaluations of 'Delicious' strains. Fruit Var. J. 45:114-120.

Dennis, Jr., F.G. 1989. Evaluating Delicious strains for color.

Proc. Michigan State Hort. Soc. 119:102-111.

Dennis, F.G., Jr. 1990. Fruit set and yield of spur and non-spur strains of 'Delicious' apple. Abstract No. 1695, p. 316, Vol. 1, Abstracts 23rd International Hort. Congress, Florence, Italy.

Fallahi, E., B.R. Simons, J.K. Fellman, M.A. Longstroth, W.M. Colt, and D.O. Ketchie. 1994. Tree growth and productivity and postharvest fruit quality in various strains of 'Delicious' apple. J. Amer. Soc. Hort. Sci. 119:389-395.

Fallahi, E., B.R. Simons, and D.O. Wilson, Jr. 1995. Leaf elemental concentrations as influenced by growth habit and strains of 'Delicious' apples. Fruit Var. J. 49:118-128.

Fisher, D.V. and D.O. Ketchie. 1981. Survey of literature on red strains of 'Delicious'. Washington State Univ Ext. Bull. 1515.

Hoblyn, T.N., N.H. Grubb, A.C. Painter, and B.L. Wates. 1956. Studies in biennial bearing. I. J. Pomol. 14:39-76.

Ketchie, D.O. 1986. Delicious strain evaluation summary. Proc. Wash- ington State Hort. Soc. 82:106-114.

Lane, W.D., R.A. MacDonald, and D.O. Ketchie. 1996. Evaluation of quality traits and yield of 28 strains of 'Delicious' apple. Fruit Var. J. 50:167-174.

Maas, V. 1970. Delicious. Ch. IV, p. 45-68. In: W.H. Upshall (ed.). North American apples: Varieties, rootstocks, outlook. Michigan State Univ. Press, East Lansing.

NC-140. 1996. Performance of the NC-140 cooperative apple rootstock planting: I. Survival, tree size, yield and fruit size. Fruit Var. J. 50:6-11.

Tukey, R.B. and J.K. Ballard. 1969a. Index of Delicious apple strains and selections. Washington State Univ. Ext. Bul. EM 3120.

Tukey, R.B. and J.K. Ballard. 1969b. Characteristics of Delicious apple strains and selections. Washington State Univ. Ext. Bul. EM 3124.

Warrington, I.J., D.C. Ferree, J.R. Schupp, F.G. Dennis, Jr., and T.A. Baugher. 1990. Strain and rootstock effects on spur characteristics and yield of 'Delicious' apple strains. J. Amer. Soc. Hort. Sci. 115:348-356.

Westwood, M.N. and H.O. Bjornstad. 1968. Effects of gibberellin $\mathrm{A}_{3}$ on fruit shape and subsequent seed dormancy of apple. HortScience 3:10-11.

Westwood, M.N. and L.T. Blaney. 1963. Non-climatic factors affecting the shape of apple fruits. Nature 200:802-803. 